\title{
Effects of PEEP on the relationship between tidal volume and total impedance change measured via electrical impedance tomography (EIT)
}

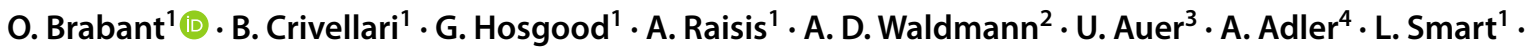 \\ M. Laurence ${ }^{1} \cdot$ M. Mosing ${ }^{1}$
}

Received: 3 August 2020 / Accepted: 6 January 2021 / Published online: 25 January 2021

(c) The Author(s), under exclusive licence to Springer Nature B.V. part of Springer Nature 2021

\begin{abstract}
Electrical impedance tomography (EIT) is used in lung physiology monitoring. There is evidence that EIT is linearly associated with global tidal volume (VT) in clinically healthy patients where no positive end-expiratory pressure (PEEP) is applied. This linearity has not been challenged by altering lung conditions. The aim of this study was to determine the effect of PEEP on VT estimation, using EIT technology and spirometry, and observe the stability of the relationship under changing lung conditions. Twelve male castrated cattle (Steer), mean age 7.8 months ( $\mathrm{SD} \pm 1.7$ ) were premedicated with xylazine followed by anaesthesia induction with ketamine and maintenance with halothane in oxygen via an endotracheal tube. An EIT belt was applied around the thorax at the level of the fifth intercostal space. Volume controlled ventilation was used. PEEP was increased in a stepwise manner from 0 to 5,10 and $15 \mathrm{cmH}_{2} \mathrm{O}$. At each PEEP, the VT was increased stepwise from 5 to 10 and $15 \mathrm{~mL} \mathrm{~kg}^{-1}$. After a minute of stabilisation, total impedance change $\left(\mathrm{VT}_{\mathrm{EIT}}\right)$, using EIT and VT measured by a spirometer connected to a flow-partitioning device $\left(\mathrm{VT}_{\text {Spiro }}\right)$ was recorded for the following minute before changing ventilator settings. Data was analysed using linear regression and multi variable analysis. There was a linear relationship between $\mathrm{VT}_{\mathrm{EIT}}$ and $\mathrm{VT}_{\text {Spiro }}$ at all levels of PEEP with an $\mathrm{R}^{2}$ of $0.71,0.68,0.63$ and 0.63 at $0,5,10$ and $15 \mathrm{cmH}_{2} \mathrm{O}$, respectively. The variance in $\mathrm{VT}_{\mathrm{EIT}}$ was best described by peak inspiratory pressure (PIP) and PEEP (adjusted $\mathrm{R}^{2} 0.82$ ) while variance in $\mathrm{VT}_{\text {Spiro }}$ was best described by PIP and airway deadspace (adjusted $\mathrm{R}^{2} 0.76$ ). The relationship between $\mathrm{VT}_{\mathrm{EIT}}$ and $\mathrm{VT}_{\text {Spiro }}$ remains linear with changes in tidal volume, and stable across altered lung conditions. This may have application for monitoring and assessment in vivo.
\end{abstract}

Keywords Anaesthesia $\cdot$ Cattle $\cdot$ Dead space $\cdot$ Pulmonary monitoring $\cdot$ Volumetric capnography

\section{Introduction}

O. Brabant

oliviabrabant22@gmail.com

1 School of Veterinary and Life Sciences, Murdoch University, Perth, WA, Australia

2 Department of Anesthesiology and Intensive Care Medicine, Rostock University Medical Centre, Rostock, Germany

3 Department of Anesthesiology, Vienna Veterinary University, Vienna, Austria

4 Department of Systems and Computer Engineering, Carlton University, Ottawa, Canada
Recent events have highlighted that lung physiology monitoring is more important than ever. Electrical impedance tomography (EIT) technology is used in ventilation studies for dynamic clinical assessment of lung states in people and more recently veterinary medicine [1-3]. The EIT allows non-invasive monitoring of ventilation distribution and lung aeration in subjects without the need for expensive imaging techniques and has potential to become a useful addition in a clinical setting for continuous lung monitoring.

Electrical impedance tomography involves thirty-two electrodes mounted to a stretchable belt being placed equidistant around the thorax injecting a weak alternating current between two electrodes and measuring the resulting voltages at all the other electrodes. This occurs in a circular 
pattern around the thorax at a speed of 40 to 50 frames per second. The measured impedance data is used to reconstruct EIT images, that represent relative changes in ventilation. EIT images are usually expressed in arbitrary units [4]. The resulting dynamic, pixelated image of relative ventilation distribution is illustrated by varying colours from dark to light $[5,6]$.

In large animals, the EIT belt is placed around the thorax at the level of the fifth spinous process. The image generated resembles a lens shaped slice of the thorax with the widest region being towards the thorax centre and the narrowest near the electrodes. The electrical current flows either side of the electrode plane creating an image area of the lung up to $10 \mathrm{~cm}$ in both directions from the electrode plane $[5,7]$. Impedance change $(\Delta Z)$ has been shown to have a direct relationship with tidal volume (VT) measured via spirometry in healthy people, pigs, small ruminants, dogs and horses with no positive end-tidal expiratory pressures (PEEP) applied [3, 7-14]. This relationship has not been established in cattle and has yet to be challenged with alterations in lung state via the application of PEEP.

Spirometry, considered gold standard, provides an estimation of global tidal volume (VT) [15]. Cattle lung volumes exceed those generated by humans therefore a flowpartitioning device is required between the endotracheal tube and the Y-piece of the circle system to accurately measure tidal volumes [16]. The gas exhaled is divided into four parts by two flow-splitter adapters connected to each other through four silicon tubes. The four silicon tubes are connected to four identical human adult flow sensors of the spirometer unit. Only one of these sensors is connected to the spirometer, allowing measurement of VT; this is then retrospectively multiplied by four to derive the actual VT [17].

Positive end-tidal expiratory pressure, is used in healthy and diseased lungs to prevent hypoxaemia [18]. The aim of PEEP is to alter physiologic conditions within the lung by maintaining end expiratory pressures above zero, preserving alveolar patency, resulting in an increase in functional residual capacity and reduction in atelectasis. This in turn alters the composition of the underlying thoracic structures by cranio-caudal shifting and alterations in the volume of vascular structures [11, 18-23].

The aim of this study was to evaluate the effect of PEEP on the relationship between impedance change measured by EIT $\left(\mathrm{VT}_{\mathrm{EIT}}\right)$ and tidal volume measured via spirometry $\left(\mathrm{VT}_{\text {Spiro }}\right)$ at set tidal volumes.

It was hypothesized that a linear relationship will exist between the two measurements at all levels of PEEP, and that PEEP does not modify this relationship.

\section{Methods}

This prospective experimental study was performed after completion of a separate study evaluating the physiological changes of cattle under general anaesthesia.

The experiment was approved by the Murdoch University Animal Ethics Committee (R2998/1).

\subsection{Animals}

Twelve steers, with a mean age of 7.8 months $(\mathrm{SD} \pm 1.7)$ and mean weight of $349 \mathrm{~kg}(\mathrm{SD} \pm 40.7)$ were included. Thoracic auscultation, heart rate, respiratory rate, temperature and rumen auscultation were performed prior to each anaesthesia. Based on this data, cattle were considered healthy for inclusion.

All animals were housed in a stall with rubber matting and straw for $48 \mathrm{~h}$ prior to commencement of the study. Food and edible bedding was restricted for a period of $24 \mathrm{~h}$. Free access to water was permitted prior to anaesthesia induction.

\subsection{Anaesthesia}

All medications used in this experiment were used as licenced according to Australian Pesticides and Veterinary Medicines Authority.

Each steer was restrained in a standing position against a tilt table. Pre-anaesthetic medication xylazine $(0.1$ $\mathrm{mgkg}^{-1}$, Ilium, Australia) was administered intravenously (IV) via the coccygeal vein. A blindfold was placed over the eyes before the steer was moved into left lateral recumbency on the tilt table. After a period of five minutes when adequate sedation had been achieved a, 14-gauge catheter was inserted into the right jugular vein after clipping and aseptic preparation of the site.

Induction of anaesthesia was achieved with ketamine (2 $\mathrm{mgkg}^{-1}$, Ilium, Australia) IV, via the jugular catheter. Orotracheal intubation was performed using either a 22 $(\mathrm{n}=2)$ or $24 \mathrm{~mm}(\mathrm{n}=10)$ internal diameter cuffed silicon tube, dependent on the size of the steer. The animal was positioned and secured into dorsal recumbency on the padded tilt table and the endotracheal tube was connected to a circle breathing system connected to a large animal anaesthetic machine and ventilator (Tafonius, Vetronic, UK). Anaesthesia was maintained with halothane (Halothane BP, Laser animal health, Australia) at an end-tidal halothane concentration $\left(\mathrm{ET}_{\mathrm{hal}}\right)$ of $0.8-1.1 \%$ delivered in 95-98\% oxygen at a flow rate of $2 \mathrm{Lmin}^{-1}$. Post induction, the right ear was clipped and aseptically prepared, a 20 -gauge auricular artery catheter was inserted to enable 
invasive blood pressure monitoring and arterial blood gas sampling. Standard monitoring of anaesthesia was conducted using a multi parameter monitor (V9203, Surgivet, Australia). The animals were allowed to breathe spontaneously as a requirement for a concurrent study on lung physiology without any specific interventions for $90 \mathrm{~min}$.

Lactated Ringers was infused at a rate of $10 \mathrm{mLkg}^{-1} \mathrm{~h}^{-1}$ throughout anaesthesia via an infusion pump (6201, Baxter, Australia). In the event of any animal showing movement or nystagmus a ketamine bolus $\left(0.3 \mathrm{mgkg}^{-1}\right)$ was administered IV. If mean arterial pressure (MAP) dropped below $75 \mathrm{mmHg}$ dobutamine (Hospira, USA) was infused IV initially at $0.03 \mathrm{mgkg}^{-1}$ increasing to $0.06 \mathrm{mgkg}^{-1}$ per hour to maintain a MAP at $75-85 \mathrm{mmHg}$. Dobutamine infusion rate was recorded at each time point.

At the end of the study period all infusions were terminated. A train-of-four (TOF) stimulation pattern $(2 \mathrm{~Hz}, 2 \mathrm{~s}$ duration, every $15 \mathrm{~s}$ ) was used with a supramaximal stimulus of $50 \mathrm{mAmp}$ over the peroneal nerve to confirm full recovery of muscle strength [24]. All animals were weaned off the ventilator using pressure support as anaesthetic depth was reduced by discontinuation of halothane delivery. When spontaneous ventilation recurred the animals were placed in lateral recumbency and transported to a shaded paddock for recovery. Catheters were removed and the trachea extubated once spontaneous swallowing had recommenced. The animals were allowed to recover fully for $24 \mathrm{~h}$ in the paddock before returning to the herd.

\subsection{Instrumentation and data collection}

Once anaesthetised, a pulmonary artery catheter was introduced through the jugular catheter under pressure guidance to determine the correct positioning. Non-conductive ultrasound gel was applied to the thorax at the 5th spinous process and 5th intercostal space without prior clipping. A custom-made EIT belt (analytica, Ottawa, Canada) consisting of 32 stainless steel electrodes joined via two rubber tubes was placed transversely crossing the 5 th intercostal space as the animals were positioned into dorsal recumbency. The belt was secured under slight tension with conforming bandage to allow adequate electrode skin contact. The electrode skin contact was inspected visually via the EIT software (BBVet, Sentec, Switzerland) before commencement of the study. A modified Graz consensus reconstruction algorithm for EIT (GREIT) was used to generate EIT images for each steer representing breathingrelated regional changes of impedance with no regions of interest applied to the images [4]. Further details on EIT technology and image reconstruction can be found elsewhere [6].

At 90 min post induction or when the $\mathrm{PCO}_{2}$ reached $13.33 \mathrm{kPa}(100 \mathrm{mmHg})$ confirmed with blood gas analysis, controlled mechanical ventilation (CMV) using volumecontrolled mode was initiated. The initial settings were 0 PEEP, set VT $5 \mathrm{mLkg}^{-1}$ at 8 breaths $\mathrm{min}^{-1}$.

Prior to initiating mechanical ventilation, muscle relaxation was induced with rocuronium $\left(0.3 \mathrm{mg} \mathrm{kg}^{-1}\right.$, Mylan, USA) administered IV, to prevent interference of spontaneous respiratory movements.

A stabilisation period of five minutes at a set VT of $5 \mathrm{~mL} \mathrm{~kg}^{-1}$ was used prior to commencing this study. Leak testing of the circuit via the flow-volume curve (closing loop) and by $<10 \%$ difference between inspiratory and expiratory tidal volume ensured the absence of a leak. Re-inflation of the endotracheal tube cuff commenced if a leak was detected.

Tidal volume $\left(\mathrm{VT}_{\text {Spiro }}\right)$ was measured using a human spirometer (NICO, Respironics Inc., USA) connected to a flow partitioning device (Fig. 1). The NICO device was calibrated following manufacturer's guidelines before each anaesthesia. Spirometry and volumetric capnography data was recorded using Datacoll@ software and analysed post completion of the study.
Fig. 1 Schematic showing the positioning of the ventilator, flow partitioning device, spirometer and EIT belt when the animal is positioned in dorsal recumbency. Airway deadspace is illustrated highlighting the difference in point of measurement

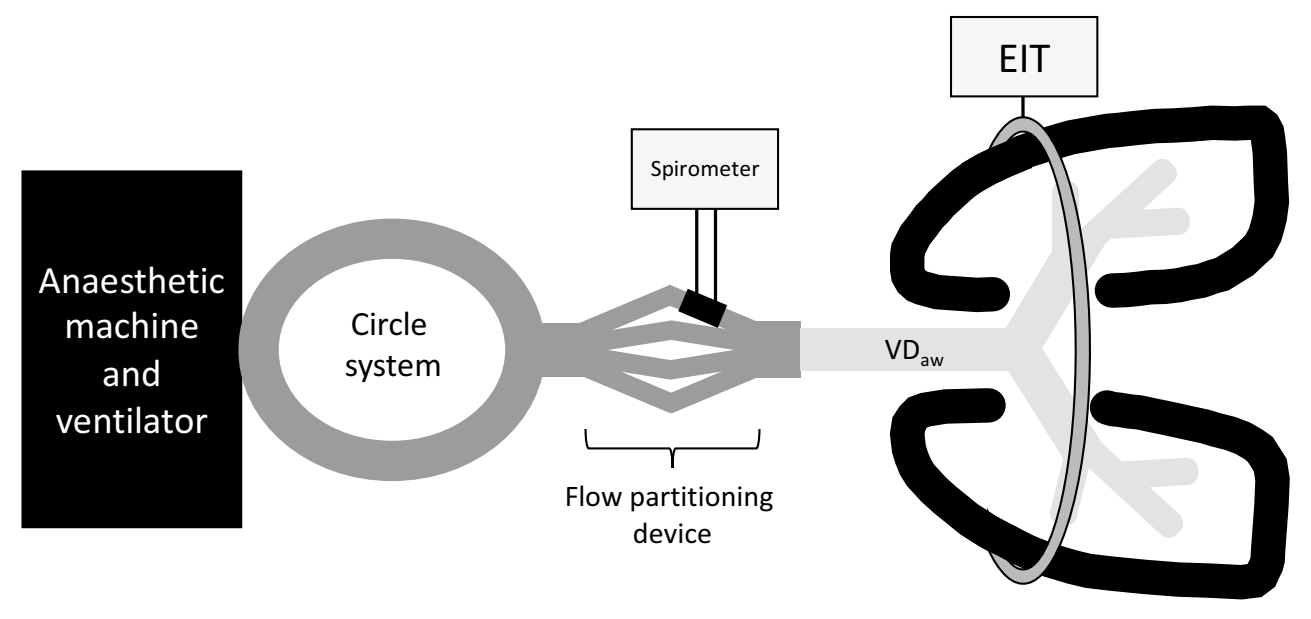


(A)

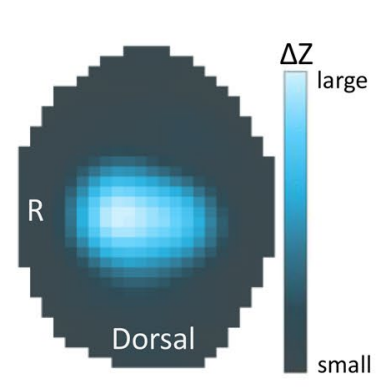

(B)

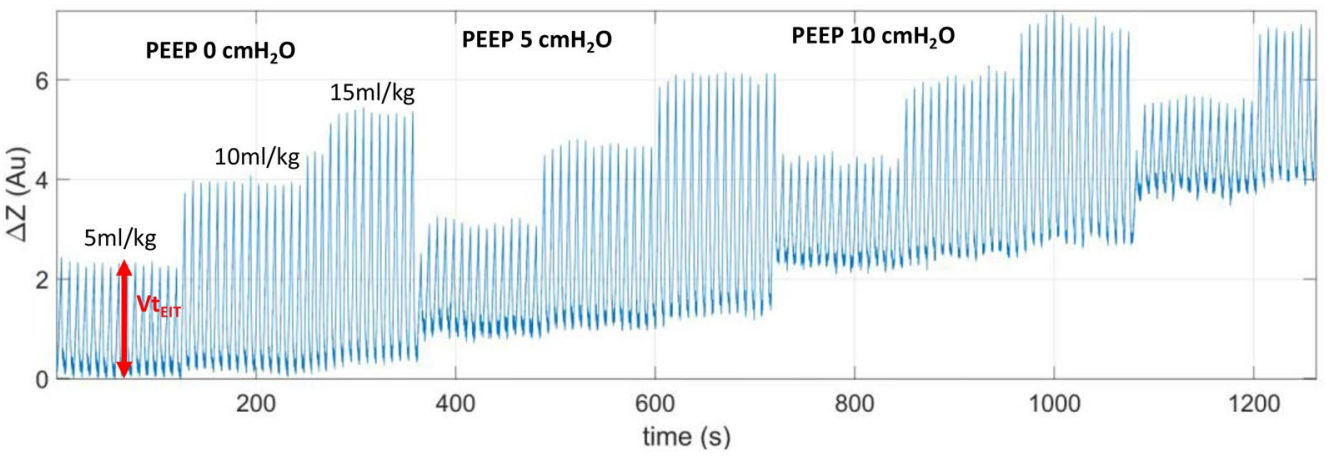

Fig. 2 Electrical impedance tomography (EIT) graphs recorded in one of twelve steers during the study: a Impedance changes visible on the EIT image were evaluated with no predefined region of interest representing the lung area $\left(\mathrm{VT}_{\text {Thorax }}\right)$. b Measurement of the global impedance change $\mathrm{VT}_{\mathrm{EIT}}$ ( $\mathrm{AU}=$ arbitrary unit) using EIT recorded

Positive end-expiratory pressure (PEEP) were increased in a stepwise manner from 0 to 5,10 and $15 \mathrm{cmH}_{2} \mathrm{O}$. At each PEEP the VT was increased stepwise from 5 to 10 and $15 \mathrm{~mL} \mathrm{~kg}^{-1}$ respectively, resulting in 12 data collection points (Fig. 2). After a minute of stabilisation at each combination of PEEP and VT, EIT and spirometry measurements were recorded for an additional minute, then the next ventilator setting established. After each change in ventilator setting, the flow-volume loop was visually inspected for leaks and the cuff re-inflated if necessary.

Termination criteria included a pre-defined cut-off of a peak inspiratory pressure (PIP) over $60 \mathrm{cmH}_{2} \mathrm{O}$. Any animal that commenced spontaneous breathing was excluded from that period of data collection.

After last steps were completed, all monitoring and measuring was ceased and the animals were allowed to recover.

\subsection{Data analysis}

Impedance changes were evaluated within the entire lung region generating a global region of interest (global ROI) by using a breath detection algorithm [25] in dedicated software (Ibex, Swisstom, Switzerland). Seven breaths were included in the analysis as the respiratory rate was set at $8 \mathrm{bpm}$ on the ventilator. This allowed the seven most stable breaths to be selected and included in the analysis. The $\mathrm{VT}_{\mathrm{EIT}}$ was calculated by subtracting the impedance change at the start of inspiration from the impedance change at the end of inspiration resulting in the mean impedance change. Spirometry measurements from the same seven consecutive stable breaths from the last minute of recorded data were used for analysis. The measured tidal volume was multiplied by four to account for the flow-splitting $\left(\mathrm{VT}_{\text {Spiro }}\right)(\mathrm{VT} 4 \mathrm{xNICO})$. The over time in seconds (s). The baseline tidal volume in this animal was $5 \mathrm{~L}$. Tidal volume increased from 5 to 10 and $15 \mathrm{ml} \mathrm{kg}^{-1}$ in a stepwise manner at each level of PEEP. PEEP was increased from 0,5 , 10 , and 15 in a stepwise manner

mean $\mathrm{VT}_{\text {Spiro }}$ of the seven breaths was included for statistical analysis; the airway and physiologic dead space values were calculated from these seven breaths, retrospectively.

Peak inspiratory pressure (PIP), pulmonary arterial pressure (mPAP), mean arterial pressure (MAP), heart rate (HR) were recorded over the same minute as data collected by EIT and spirometry. Physiologic dead space $\left(\mathrm{VD}_{\text {Phys }}\right)$ and airway deadspace $\left(\mathrm{VD}_{\mathrm{Aw}}\right)$ were calculated retrospectively from the spirometry recordings using the Bohr and Enghoff equations [26] (Table 1).

\subsection{Statistical analysis}

Linear regression was used to explore the relationship between the response $\mathrm{VT}_{\mathrm{EIT}}$ and the known tidal volume $\left(\mathrm{VT}_{\text {Spiro }}\right)$. The relationship was explored within each PEEP setting, to view the stability of the linearity over the range of tidal volumes. Each paired reading of $\mathrm{VT}_{\mathrm{EIT}}$ and $\mathrm{VT}_{\text {Spiro }}$ for each animal at the three VT settings was included for each PEEP, acknowledging that some co-linearity might exist between measurements in each steer, but avoiding confounding an unstable relationship within each steer by averaging the three readings since they were obtained at different VT settings.

The estimates, SE and 95\% Confidence Intervals of the intercept and slope, and the $\mathrm{R}^{2}$ for each PEEP analysis are reported and were compared. Multivariable regression was used to explore possible explanatory variables for variance in $\mathrm{VT}_{\mathrm{EIT}}$ and in $\mathrm{VT}_{\text {Spiro }}$. 


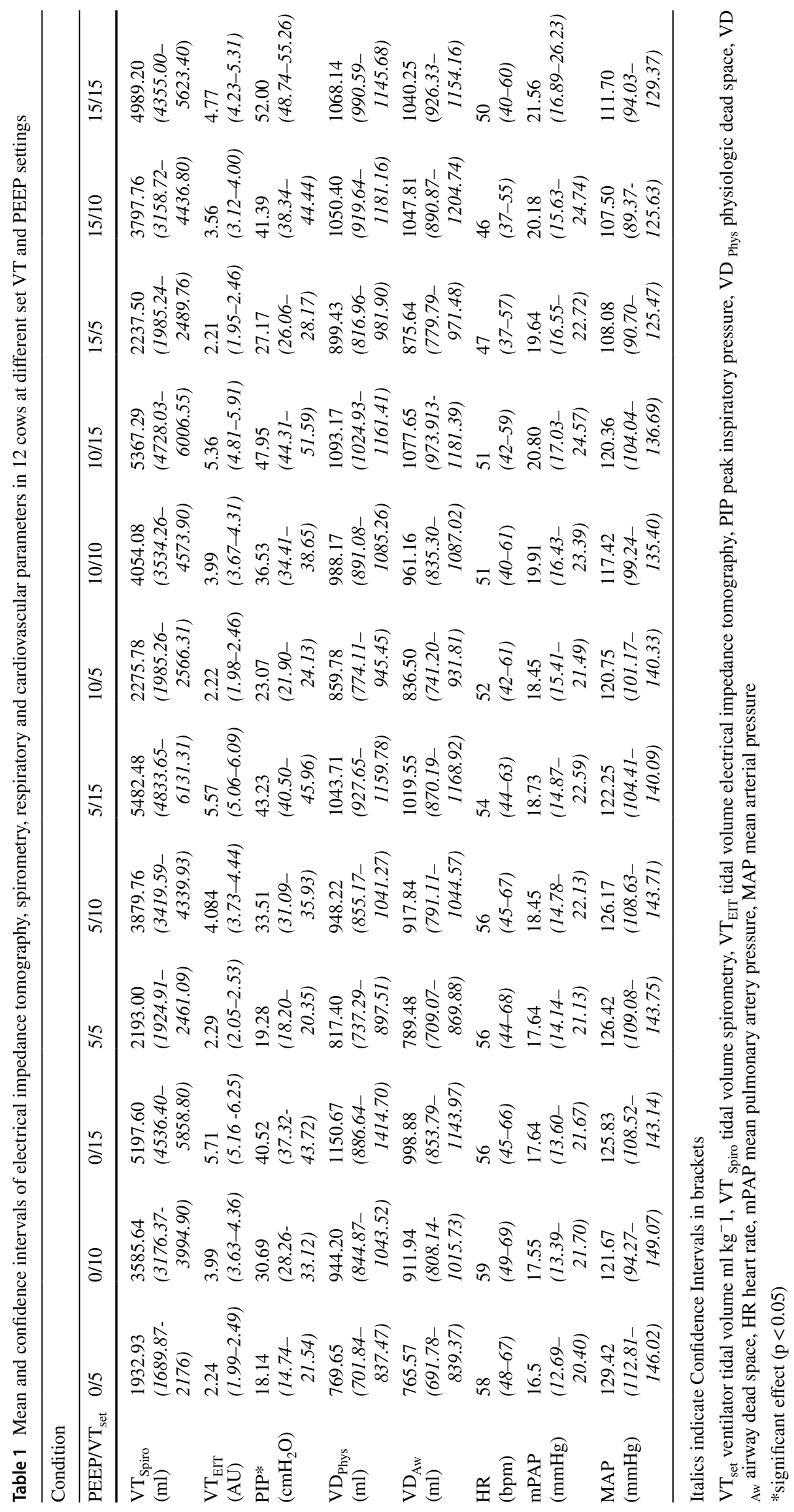


Fig. 3 Flow diagram shwing the number of steers included in this study and drop out at each measurement point. $\mathrm{VT}_{\text {set, }}$ tidal volume set by ventilator in $\mathrm{ml}$ $\mathrm{kg}^{-1}$, PEEP, positive end expiratory pressure

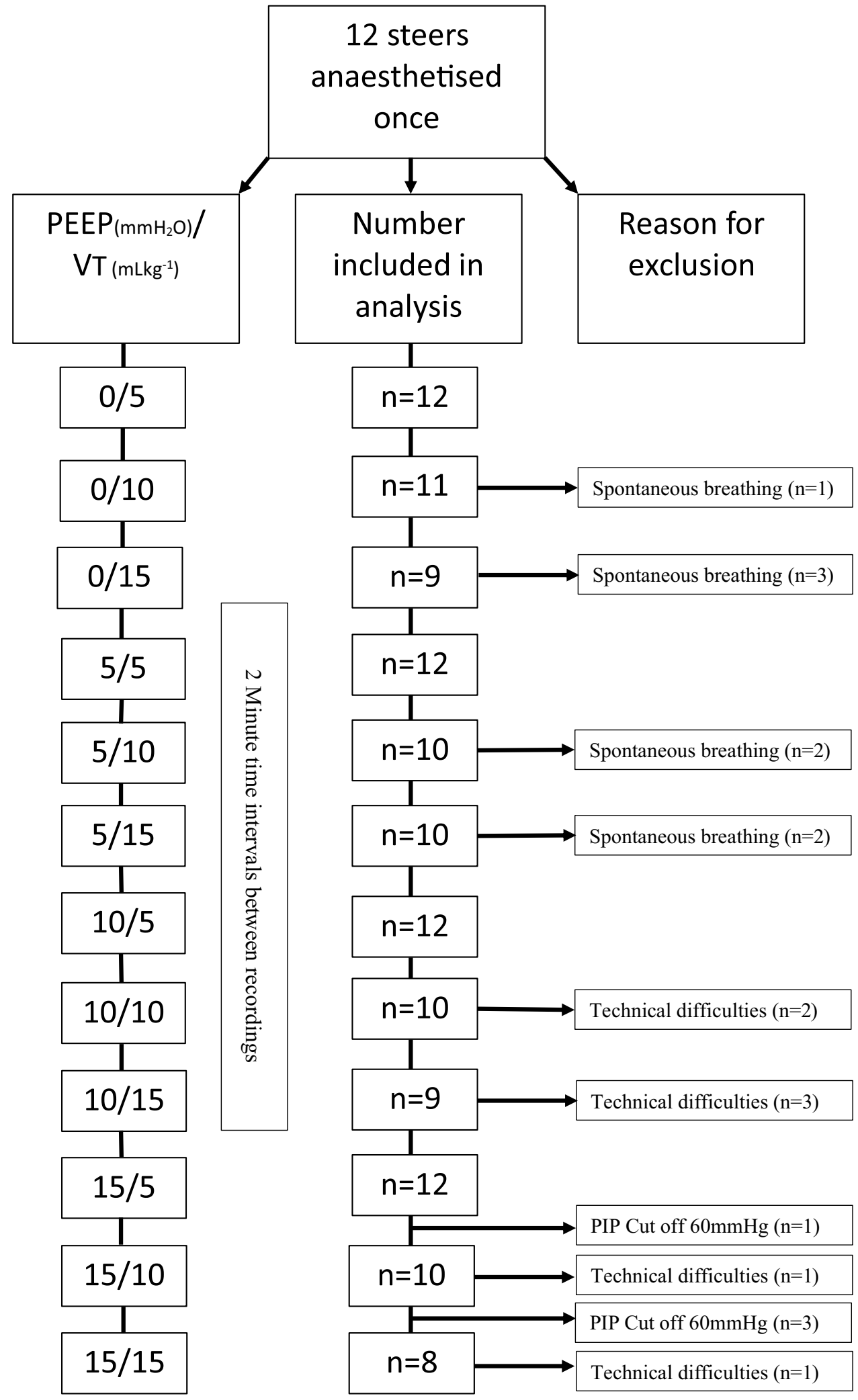

\section{Results}

All animals recovered from anaesthesia without complication. Data from all twelve animals were included for data analysis. One animal was started on a dobutamine infusion but was included since the end of study was 
reached. One animal required a bolus of ketamine, leading to the omission of one data point. Four of the twelve animals exceeded the cut off limit of $60 \mathrm{mmHg}$, obviating four data points. Three animals had spontaneous breathing, obviating seven data points. Seven data points were lost due to technical difficulties in spirometry or EIT readings (Fig. 3). In total 125 out of a possible 144 mean data points were included in the analysis.

Descriptive statistics (means and 95\% confidence intervals) of $\mathrm{VT}_{\mathrm{EIT}}, \mathrm{VT}_{\text {Spiro }}$ and other respiratory and cardiovascular variables including PIP, $\mathrm{VD}_{\mathrm{Phys}}, \mathrm{VD}_{\mathrm{Aw}}, \mathrm{HR}, \mathrm{mPAP}$ are displayed (Table 1). The respiratory rate was set on the ventilator at $8 \mathrm{bpm} 8.8(7.94-9.73)$. The ventilator VT was between $1.76 \mathrm{~L}(1.7-1.82), 3.46 \mathrm{~L}(3.34-3.58)$ and $5.22 \mathrm{~L}$ (5.05-5.39) for 5,10 and $15 \mathrm{~mL} \mathrm{~kg}^{-1}$ respectively compared with the mean $\mathrm{VT}_{\text {Spiro }}$ of $2.16 \mathrm{~L}(2.04-2.28), 3.9 \mathrm{~L}$ (3.74-4.07), and 5.25L (5.01-5.48) respectively.
There was a linear relationship between $\mathrm{VT}_{\text {EIT }}$ and $\mathrm{VT}_{\text {Spiro }}$ across all PEEP with an $\mathrm{R}^{2} 0.71(0.67-1.07), 0.68$ (0.60-0.99), $0.63(0.55-0.98)$ and $0.63(0.50-0.90)$ for $0,5,10,15 \mathrm{cmH}_{2} \mathrm{O}$ respectively (Table 2). The regression slope did not vary significantly at all levels of PEEP with a slope of $\left(\mathrm{VT} \times 10^{-3}\right) 0.87$ (0.67-1.07), $0.80(0.60-0.99), 0.77$ $(0.55-0.98)$ and $0.70(0.50-0.90)$ at $0,5,10,15$ PEEP respectively (Table 2) All estimates for intercepts and slope fell within the $95 \%$ confidence interval of each model (Fig. 4).

Exploring the explanation of variance in $\mathrm{VT}_{\text {Spiro }}$ showed it was singularly best explained by PIP $\left(\mathrm{R}^{2} 0.67\right)$. Addition of $\mathrm{VD}_{\mathrm{Aw}}$ improved the explanation to an adjusted $\mathrm{R}^{2}$ of 0.76 . Similarly, the variance in $\mathrm{VT}_{\text {EIT }}$ was singularly explained by PIP $\left(R^{2} 0.65\right)$. Addition of PEEP improved the explanation to and adjusted $\mathrm{R}^{2}$ of 0.81 . Interestingly, $\mathrm{VD}_{\mathrm{Aw}}$ singularly only contributed 0.2 to the variance in $\mathrm{VT}_{\mathrm{EIT}}$. All

Table 2 Coefficient of determination $\left(\mathrm{R}^{2}\right)$, standard error (SE) with 95\% confidence intervals for each PEEP level averaged from all twelve bovines

\begin{tabular}{|c|c|c|c|c|c|c|c|c|c|}
\hline \multirow{2}{*}{$\begin{array}{l}\text { Peep } \\
0\end{array}$} & \multirow{2}{*}{$\begin{array}{l}\text { Intercept } \\
.84378\end{array}$} & \multirow{2}{*}{$\frac{\mathrm{SE}}{.37712}$} & \multicolumn{2}{|c|}{$95 \% \mathrm{CI}$ of the intercept } & \multirow{2}{*}{$\begin{array}{l}\text { Slope }(\mathrm{Vt}) \times 10^{-3} \\
.86991\end{array}$} & \multirow{2}{*}{$\frac{\mathrm{SE}(\times 10-3)}{.10163}$} & \multicolumn{2}{|c|}{$95 \%$ CI of the slope } & \multirow{2}{*}{$\begin{array}{l}\mathrm{R}^{2} \\
.7095\end{array}$} \\
\hline & & & 0.1046248 & 1.5829352 & & & 0.6707152 & 1.0691048 & \\
\hline 5 & .88539 & .40363 & 0.0942752 & 1.6765048 & .79837 & .09995 & 0.602468 & 0.994272 & .6802 \\
\hline 10 & .82409 & .44155 & -0.041348 & 1.689528 & .76805 & .11013 & 0.5521952 & 0.9839048 & .6265 \\
\hline 15 & .88613 & .37738 & 0.1464652 & 1.6257948 & .70210 & .10069 & 0.5047476 & 0.8994524 & .6264 \\
\hline
\end{tabular}

Fig. 4 Relationship and confidence interval between $\mathrm{VT}_{\mathrm{EIT}}$ and $\mathrm{VT}_{\text {Spiro }}$ measured by electrical impedance tomography (EIT) and spirometry measurements in twelve anaesthetised mechanically ventilated steers at PEEP 0, PEEP 5, PEEP 10 and PEEP 15 . Spirometry was measured and as a volume $(\mathrm{mL})$ and EIT as impedance change $\Delta \mathrm{Z}$ (AU $=$ arbitrary unit) represented by full circles
PEEP 0

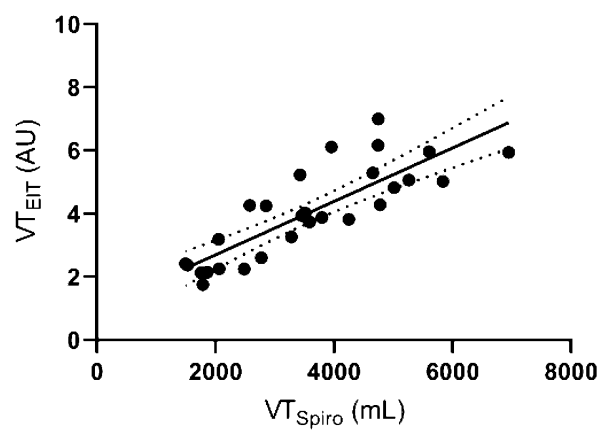

PEEP 10

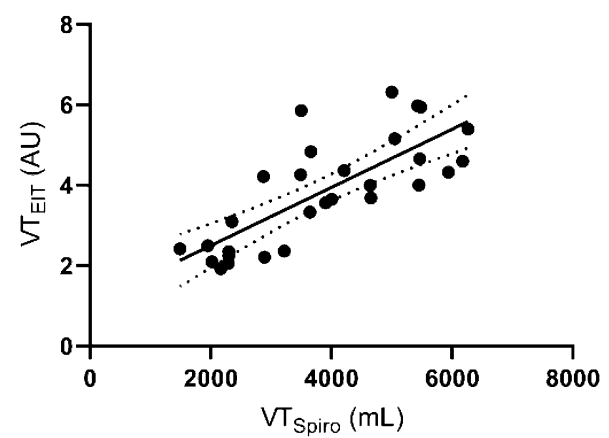

PEEP 5 -

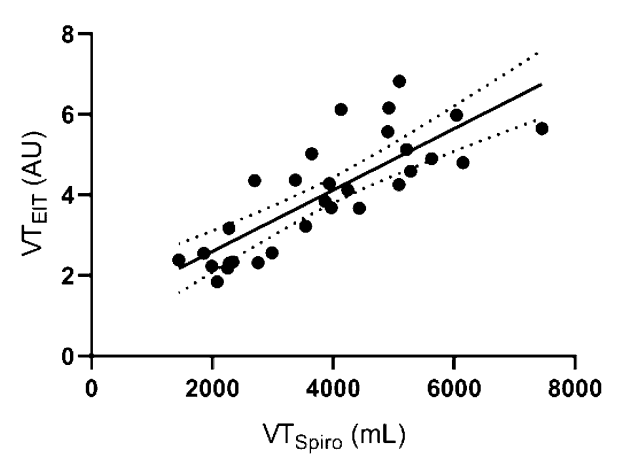

PEEP15

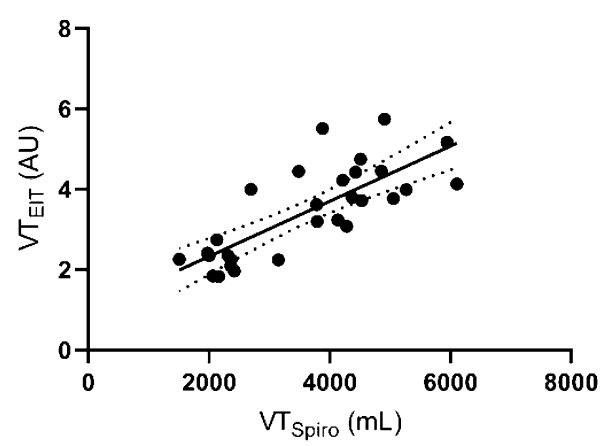


other variables including $\mathrm{VD}_{\text {Phys }}, \mathrm{HR}$, mPAP and MAP had marginal impact on the variance $\mathrm{VT}_{\mathrm{EIT}}$ or $\mathrm{VT}_{\text {Spiro }}$.

\section{Discussion}

The findings of this study confirmed a linear relationship between total impedance change measured by EIT and the tidal volume measured by spirometry. This relationship was persistent over a range of volumes and different lung states produced by increasing PEEP.

Commercially available spirometry in sedated, anesthetised or non-compliant subjects requires tubing and equipment in addition to ventilatory equipment [10, 15]. Specific circumstances such as; high flow rates or longterm use, CPAP helmets or where subjects can deteriorate quickly even when on oxygen, prevent accurate measurements with spirometry and capnography. Although EIT does not yet provide a direct measurement of tidal volume in $\mathrm{mL}$, it has shown promise in a clinical setting as a useful estimate for non-invasive monitoring, visualising trends and changes in lung status [18].

This study is in agreement with previous work showing a linear relationship in several species exists between $\mathrm{VT}_{\text {EIT }}$ and $\mathrm{VT}_{\text {Spiro }}$ using no PEEP $[3,8,10]$ and indirectly PEEP [11, 27, 28]. Linearity was stable when breathing amplitude, extremes in lung volume and anthropometric characteristics varied [27, 29]. However when PEEP was used to compare impedance change and volume change using nitrogen washout technique linearity was poor in critically ill patients [30]. It has been suggested that belt position can influence this relationship in human studies [22]. Therefore careful of positioning of the belt was considered. The $5^{\text {th }}$ intercostal space position provided the maximal lung area with minimal interference from the heart and the abdominal contents. This was confirmed with post-mortem, computer tomography and anatomical models [31].

A spirometer has been used in this study to measure tidal volume. With larger VTs and a PIP of up to $60 \mathrm{cmH} 2 \mathrm{O}$ as seen in this study, the loss of volume from the ventilator would be in the order of $1.8 \mathrm{~L}$ as the compliance of the hoses of the breathing system is $30 \mathrm{~mL} / \mathrm{cmH} 2 \mathrm{O}$ (verified in an in-vitro set-up) [10]. Therefore it was decided a spirometer provided a more accurate measure of the volume delivered to the animal.

In this study a marginal decrease in linearity is seen at higher PEEP and PIP. The EIT measures the total impedance change within the thorax including that created by perfusion. This impedance change created by perfusion is pulsatile in nature and much smaller than the ventilation impedance [11]. There is an assumption that the influence of perfusion is greater at lower tidal volumes. This is due to a larger volume of blood within the thorax and perfusion making up a larger portion of total impedance at lower tidal volumes and pressures. This is reflected in the results at lower volumes with a bias in the spirometer at lower volumes that decreases at higher volumes. However, at higher intrathoracic pressures extravascular lung water and blood is forced back in the intravascular space causing a reduction in blood volume and movement within the lung tissue this may have a small effect on linearity [23, 32-35].

At higher PEEP and PIP there is also likely to be more distension of the airways and a reduction in atelectasis by maintaining alveolar opening pressures, thus altering lung state [33]. Measurements made using EIT represent a lensshaped slice of the thorax. This is influenced by PIP, PEEP and airway compliance within the lens $[6,11]$. Spirometry measures tidal volume at the proximal end of the airway. This includes the respiratory airways but does not account for the compliance of those airways $[3,15,36]$ (Fig. 1). This explains the influence on linearity at higher levels of PEEP and is reflected in the results with variance in $\mathrm{VT}_{\mathrm{EIT}}$ best explained by PIP and PEEP whereas variance in $\mathrm{VT}_{\text {Spiro }}$ best explained by PIP and $\mathrm{VD}_{\mathrm{Aw}}$.

At higher PEEP, global increased lung pressure leads to caudal areas of the lung becoming relatively more active than the already open less compliant middle portion [37]. The result is the opening of alveoli previously closed under lower PEEP and not captured in the lens shaped slice of the EIT. Coupled with inhomogeneous ventilation distribution in the cranial-caudal plane, local in-homogenies in ventilation with changes in PEEP have been reported [11, 30, 38] and would also explain the observed weakening of the relationship between $\mathrm{VT}_{\text {Spiro }}$ and $\mathrm{VT}_{\mathrm{EIT}}$ at higher PEEP.

Steers representing cattle were used for this lung model to illustrate the linearity between $\mathrm{VT}_{\mathrm{EIT}}$ and $\mathrm{VT}_{\text {Spiro }}$ because of their large tidal volumes, well-developed interlobular septa reducing collateral ventilation, ability to shift ventilation and rapid development of atelectasis during anaesthesia [39-41]. This was confirmed with a mean venous admixture of $52 \%$ in our cattle before the start of the study. The large tidal volumes and PEEP changes caused alterations of lung status by increasing transpulmonary pressures leading to airway recruitment and increased functional residual capacity and expansion of the thorax [11, 18, 42-47]. To allow generalisability to other species no specific anatomical mesh was applied allowing technical comparison of the relationship [32].

Limitations of this study include the need to use a flow partitioning device in addition to the spirometer for high flow tidal volumes however, the accuracy of this device over a wide range of flows has been validated elsewhere $[16,48]$. In an attempt to reduce the impact of lung volume increase for $\mathrm{VT}_{\mathrm{EIT}}$ analysis, it was decided that no lung region of interest should be employed as high VT can over inflate 
the lungs and extend out of the region of interest (Fig. 2) [10]. With no region of interest applied the reconstruction is reasonable however, in the analysis impedance changes that have not derived from a change in ventilation but from either the heart, changes in blood flow and abdominal organs moving in and out of the EIT plane may have been included leading to an increase in random error $[23,34,35,37,38$, 48]. Nevertheless, as in other studies the influence of these impedance changes was not significant on the overall $\mathrm{VT}_{\mathrm{EIT}}$ [11]. Future studies need to confirm our finding in clinical settings over a longer time period.

\section{Conclusion}

Linearity exists between $\mathrm{VT}_{\text {EIT }}$ and $\mathrm{VT}_{\text {Spiro }}$ and this relationship remains when lung states are altered by increasing PEEP when cattle in dorsal recumbency are employed as a model using a single electrode plane. This suggests that electrical impedance tomography is a promising tool as a surrogate for spirometry in the clinical monitoring of tidal volume over time. Further work into the plane of view of the lungs by the EIT is needed to eliminate influencing factors at higher PEEP, where there is a marginal reduction in this linearity.

Author contributions $\mathrm{OB}, \mathrm{BC}$ selected the study design, acquired the data, drafted, and completed the manuscript for publication. AR, ML acquired the data and revised the manuscript and approved it for publication. AW, UA reconstructed and analysed the data, revised the manuscript and approved it for publication. GH, LS performed the statistical analysis, revised the manuscript and approved for publication. AA selected the study design and revised the manuscript and approved it for publication. MM selected the study design, acquired the data and gave the final approval for publication. All authors have read and approved the final manuscript.

Funding This study was funded with institutional research money from Murdoch University, Western Australia.

\section{Compliance with ethical standards}

Conflict of interest The authors declare that they have no conflict of interest.

Research involving human and/or animals This experimental study was reviewed and approved by the ethics committee (R2998/1). All procedures performed in animals were in accordance with the ethical standards of Murdoch University Animal Ethics Committee.

\section{References}

1. Reifferscheid F, Elke G, et al. Regional ventilation distribution determined by electrical impedance tomography: reproducibility and effects of posture and chest plane. Respirology. 2011;16(3):523-31.

2. Mosing M, Marley-Voquer C, et al. Regional distribution of ventilation in horses in dorsal recumbency during spontaneous and mechanical ventilation assessed by electrical impedance tomography: a case series. Vet Anaesth Analg. 2017;44(1):127-32.

3. Frerichs I, Dargaville P, et al. Electrical impedance tomography: a method for monitoring regional lung aeration and tidal volume distribution? Intensive Care Med. 2003;29(12):2312-6.

4. Adler A, Arnold JH, et al. GREIT: a unified approach to 2D linear EIT reconstruction of lung images. Physiol Meas. 2009;30(6):S35.

5. Frerichs I, Hahn G, Hellige G. Thoracic electrical impedance tomographic measurements during volume controlled ventilation-effects of tidal volume and positive end-expiratory pressure. IEEE Trans Med Imaging. 1999;18(9):764-73.

6. Frerichs I, Amato MBP, et al. Chest electrical impedance tomography examination, data analysis, terminology, clinical use and recommendations: consensus statement of the translational EIT development study group. Thorax. 2017;72(1):83.

7. Victorino J, Borges JB, et al. Imbalances in regional lung ventilation - a validation study on electrical impedance tomography. Am J Respir Crit Care Med. 2004;169(7):791-800.

8. Adler A, Amyot, et al. Monitoring changes in lung air and liquid volumes with electrical impedance tomography. J Appl Physiol. 1997;83(5):1762.

9. Balleza-Ordaz M, Perez-Alday E, et al. Tidal volume monitoring by electrical impedance tomography (EIT) using different regions of interest (ROI): calibration equations. Biomed Signal Process Control. 2015;18:102-9.

10. Mosing M, Waldmann AD, et al. Monitoring of tidal ventilation by electrical impedance tomography in anaesthetised horses. Equine Vet J. 2018;51:222-6.

11. Hinz J, Hahn G, et al. End-expiratory lung impedance change enables bedside monitoring of end-expiratory lung volume change. Intensive Care Med. 2003;29(1):37.

12. Fagerberg A, Stenqvist O, Aneman A. Monitoring pulmonary perfusion by electrical impedance tomography: an evaluation in a pig model. Acta Anaesthesiol Scand. 2009;53(2):152-8.

13. Grant C, Fraser J, et al. The assessment of regional lung mechanics with electrical impedance tomography: a pilot study during recruitment manoeuvres. Intensive Care Med. 2009;35(1):166-70.

14. Ambrosio AM, Carvalho-Kamakura TPA, et al. Ventilation distribution assessed with electrical impedance tomography and the influence of tidal volume, recruitment and positive endexpiratory pressure in isoflurane-anesthetized dogs. Vet Anaesth Analg. 2017;44(2):254-63.

15. Davey AJ, Diba A, Ward CS. Ward's anaesthetic equipment. 6th ed. Edinburgh: Elsevier; 2012.

16. Schramel JP, Wimmer K, et al. A novel flow partition device for spirometry during large animal anaesthesia. Vet Anaesth Analg. 2014;41(2):191-5.

17. Ambrisko TD, Lammer $\mathrm{V}$, et al. In vitro and in vivo evaluation of a new large animal spirometry device using mainstream $\mathrm{CO} 2$ flow sensors. Equine Vet J. 2014;46(4):507-11.

18. Wild M, Alagesan K. Peep and Cpap. Br J Anaesth. 2001;1(3):89-92.

19. Lachmann B. Open up the lung and keep the lung open. Intensive Care Med. 1992;18(6):319-21.

20. Frerichs I, Schmitz G, et al. Reproducibility of regional lung ventilation distribution determined by electrical impedance 
tomography during mechanical ventilation. Physiol Meas. 2007;28(7):S261-7.

21. Powers SR Jr, Mannal R, et al. Physiologic consequences of positive end-expiratory pressure (PEEP) ventilation. Ann Surg. 1973;178(3):265-72.

22. Karsten J, Stueber T, et al. Influence of different electrode belt positions on electrical impedance tomography imaging of regional ventilation: a prospective observational study. Crit Care. 2016;20(1):1161-9.

23. Peters J, Hecker B, et al. Regional blood volume distribution during positive and negative airway pressure breathing in supine humans. J Appl Physiol. 1993;75(4):1740-7.

24. Mosing M, Auer U, et al. Reversal of profound rocuronium block monitored in three muscle groups with sugammadex in ponies. Br J Anaesth. 2010;105(4):480-6.

25. Khodadad D, Nordebo S, et al. Optimized breath detection algorithm in electrical impedance tomography. Physiol Meas. 2018;39(9):0967-3334.

26. West JB. Respiratory physiology: the essentials. 10th ed. Philadelphia: Wolters Kluwer; 2016

27. Marquis F, Coulombe N, et al. Electrical impedance tomography's correlation to lung volume is not influenced by anthropometric parameters. J Clin Monit Comput. 2006;20(3):201-7.

28. Becher TH, Bui S, et al. Assessment of respiratory system compliance with electrical impedance tomography using a positive end-expiratory pressure wave maneuver during pressure support ventilation: a pilot clinical study. Crit Care. 2014;18(6):679.

29. Ngo C, Leonhardt S, et al. Linearity of electrical impedance tomography during maximum effort breathing and forced expiration maneuvers. Physiol Meas. 2017;38(1):77-86.

30. Bikker IG, Leonhardt $\mathrm{S}$, et al. Lung volume calculated from electrical impedance tomography in ICU patients at different PEEP levels. Intensive Care Med. 2009;35(8):1362.

31. Brabant O, Waldmann A, Buss P, Mosing M (2018) Construction of a finite element model in two large species for EIT application. Proceedings of Science Week Anaesthesia chapter, Gold Coast

32. Thurk F, Boehme S, et al. Effects of individualized electrical impedance tomography and image reconstruction settings upon the assessment of regional ventilation distribution: comparison to 4-dimensional computed tomography in a porcine model. PLoS ONE. 2017;1(8):0182215.

33. Luecke T, Roth H, et al. PEEP decreases atelectasis and extravascular lung water but not lung tissue volume in surfactant-washout lung injury. Intensive Care Med. 2003;29(11):2026-33.

34. Gattinoni L, Pesenti A, et al. Relationships between lung computed tomographic density, gas exchange, and peep in acute respiratory failure. Anesthesiology. 1988;69(6):824-32.
35. Tang R, Huang Y, et al. Relationship between regional lung compliance and ventilation homogeneity in the supine and prone position. Acta Anaesthesiol Scand. 2012;56(9):1191-9.

36. Zhao Z, Möller K, et al. Evaluation of an electrical impedance tomography-based global inhomogeneity index for pulmonary ventilation distribution. Intensive Care Med. 2009;35(11):1900-6.

37. Nieszkowska A, Lu Q, et al. Incidence and regional distribution of lung overinflation during mechanical ventilation with positive end-expiratory pressure. Crit Care Med. 2004;32(7):1496-503.

38. Kobler A, Hartnack S, et al. Evaluation der Messgenauigkeit von Atemvolumina des Anästhesiegerätes Tafonius ${ }^{\circledR}$ in vitro und in vivo. Pferdeheilkunde. 2016;32(5):449-56.

39. Tokics L, Hedenstierna G, et al. Lung collapse and gas exchange during general anesthesia: effects of spontaneous breathing, muscle paralysis, and positive end-expiratory pressure. Anesthesiology. 1987;66(2):157-67.

40. Hedenstierna $\mathrm{G}$, Lundquist $\mathrm{H}$, et al. Pulmonary densities during anaesthesia. An experimental study on lung morphology and gas exchange. Eur Respir J. 1989;2(6):528.

41. Nyman G, Funkquist B, et al. Atelectasis causes gas exchange impairment in the anaesthetised horse. Equine Vet J. 1990;22(5):317.

42. Dyce KM. Essentials of bovine anatomy. Philadelphia: Lea and Febiger; 1971.

43. Tusman G, Böhm SH, et al. Alveolar recruitment strategy' improves arterial oxygenation during general anaesthesia. Br J Anaesth. 1999;82(1):8-13.

44. McLaughlin RF, Tyler WS, Canada RO. A study of the subgross pulmonary anatomy in various mammals. Am J Anat. 1961;108(2):149-65.

45. Parent RA. Comparative biology of the normal lung. 2nd ed. London: Academic Press; 2015.

46. Cutaia M, Rounds S. Hypoxic pulmonary vasoconstriction. Physiologic significance, mechanism, and clinical relevance. Chest. 1990;97(3):706-18.

47. Wagner PD, Saltzman H, West J. Measurement of continuous distributions of ventilation-perfusion ratios: theory. J Appl Physiol. 1974;36(5):588-99.

48. Grychtol B, Lionheart WRB, et al. Impact of model shape mismatch on reconstruction quality in electrical impedance tomography. IEEE Trans Med Imaging. 2012;31(9):1754-60.

Publisher's Note Springer Nature remains neutral with regard to jurisdictional claims in published maps and institutional affiliations. 